\title{
EVALUATION OF ASHA PROGRAMME IN SELECTED BLOCK OF RAISEN DISTRICT OF MADHYA PRADESH UNDER THE NATIONAL RURAL HEALTH MISSION
}

Bhagwan Waskel ${ }^{1}$, Sanjay Dixit ${ }^{2}$, Rama Singodia ${ }^{3}$, D.K. Pal ${ }^{4}$, Manju Toppo ${ }^{5}$, S.C. Tiwari ${ }^{6}$, Satish Saroshe $^{7}$

\section{HOW TO CITE THIS ARTICLE:}

Bhagwan Waskel, Sanjay Dixit, Rama Singodia, D.K. Pal, Manju Toppo, S.C. Tiwari, Satish Saroshe. "Evaluation of ASHA Program in selected block of Raisen District of Madhya Pradesh under The National Rural Health Mission". Journal of Evolution of Medical and Dental Sciences 2014; Vol. 3, Issue 03, January 20; Page: 689-694, DOI:10.14260/jemds/2014/1887

BACKGROUND: Currently Government of India is providing comprehensive integrated health care to the rural people under the umbrella of National Rural Health Mission (NRHM). A village level community health worker "Accredited Social Health Activist" (ASHA)' acts as an interface between the community and the public health system. OBJECTIVE: To assess the socio-demographic profile of ASHA workers and to evaluate their knowledge and practice of their responsibilities. SETTINGS \& DESIGN: Cross-sectional study, Obedullaganj and Sanchi blocks of Bhopal district of Madhya Pradesh. METHODS \& MATERIAL: A cross-sectional study was conducted at obedullaganj and Sanchi in the Bhopal district of Madhya Pradesh for a period of 1 year from October 2007 to October 2008 The study participants were trained ASHA workers working in the Sanchi \& Obedullaganj block. Statistical Analysis: Chi Square test using MS excel \& SPSS ver 17. RESULT: Majority of ASHA workers were aware about helping in immunization, accompanying clients for delivery, providing ANC and family planning services as a part of responsibility. About 99\% of ASHAs knew registration of births and deaths, assisting Auxiliary Nurse Midwife (ANM) in village health planning, creating awareness on basic sanitation and personal hygiene. CONCLUSION: Despite the training given to ASHAs, lacunae still exists in their knowledge regarding various aspects of child health morbidity. Monthly meetings can be used as a platform for the reinforcement of various aspects of child health. Periodical refresher training should be conducted for all of the recruited ASHA workers. In the future training sessions, more emphasis should be given to high risk cases requiring prompt referral.

INTRODUCTION: The Government of India launched the National Rural Health Mission (NRHM) on 12th April 2005, to provide accessible, accountable, affordable, effective and reliable primary health care, especially to the poor and vulnerable sections of the population. ${ }^{1,2}$ The Mission adopts a synergistic approach by relating health to determinants of good health viz. segments of nutrition, sanitation, hygiene and safe drinking water. ${ }^{3}$ One of the key components of the mission is creating a band of female health volunteers, appropriately named "Accredited Social Health Activist" (ASHA) in each village within the identified States. These village level community health workers would act as a 'bridge' or an interface between the rural people and health service outlets and would play a central role, in achieving national health and population policy goals. ${ }^{4,5}$ Framework of the NRHM underlines ASHA as a health activist in the community. ${ }^{5}$ She is expected to Provide primary medical care with her kit, Control of diseases by information, education, sanitation and surveillance, antenatal, natal \& postnatal services to women, counseling on family planning, safe abortion, child Immunization and Vitamin A supplementations, change in behavior in breast feeding, birth spacing, sex discrimination, child marriage, girls education, care of the child especially newborn, household 
survey, collaborating with health functionaries, working with community for disease control, to create awareness on health and its determinants, mobilize the community towards local health planning, and increase the utilization of the existing health services.6,7 The current study has been designed for ascertaining how efficient the ASHAs are to play their defined roles effectively. They can play an important role in identifying problems at the earliest and help in improving community health status. Therefore the present study was undertaken to understand the functioning of the ASHAs in the community.

MATERIALS AND METHODS: Cross sectional study was carried out in Sanchi \& Obedullaganj Block, Raisen district which is the rural field practice area of the department of Community Medicine, Gandhi medical college Bhopal during the period of oct.2007 to Oct. 2008.

Raisen district covers seven blocks, and total 772 ASHA were selected. The present study was conducted in Sanchi \& Obedullaganj Block where 101 ASHA in Sanchi and 123 in Obedullaganj were selected \& trained from August 2006 in batch wise throughout the 2006. They were working as ASHA since 2007. In Obedullaganj block out of 123 ASHA, only 110 ASHA were planned to be interviewed. Rest 13 ASHA were not included because they did not have certificate of the first induction training which was given by NGO. And out of 110 ASHA, 3 ASHA left their job, so 107 ASHA were interviewed finally. In Sanchi block out of total 101 ASHA, 99 ASHA were interviewed and rest 2 ASHAs were not working as ASHA at the time of study. Thus a total of 206 ASHA formed the study subject.

Inter-personal Interview method using Pre-designed semi-structured questionnaire was adopted for collecting the data. All the registered ASHA in Obedullaganj and Sanchi block of Bhopal were interviewed at the time of monthly meeting at PHC, sub-centre or every Tuesday (Immunization day) at sub centre and also during field visits. Written Informed consent was taken from all ASHA. The knowledge of ASHA were graded according to cardinal sign and symptoms of diseases, modes of transmission and prevention related to diseases immunization, FP, antenatal care and breast feeding.

Each question was given 5 marks and a total of 50 marks were allotted to the knowledge questions. Each ASHA was graded good, average and poor according to the responses she gave.

Good : Range between 36-50

Average : $\quad$ Range between 20-35

Poor : $\quad$ Range less than 20

\section{RESULTS:}

Socio-demographic profile of ASHA functionaries: Data of 206 ASHA workers was included and analyzed in the study. Majority 140 (67.69\%) of the ASHA workers were in the age group of 20-29 years. Mean age of ASHA workers was 27 years. Most 194 (94.17\%) of the ASHA workers were Hindus. Most 86 (41.74\%) of ASHA workers had completed 8th std followed by 43 (20.9\%) ASHA who were high school pass and only 13 (6.3\%) were educated upto post-graduation. Of the 206 ASHAs interviewed 193 were married accounting for $93.68 \%$ of the subjects. 206 (100\%) of ASHA workers completed training before working as ASHA. The majority had been trained at district level that is 197 (95.63\%). In general ASHA workers were satisfied and happy with their training. 128 (62.14\%) out of 206 ASHAs had kit. 
Table no. 1 shows large proportion of ASHAs had good knowledge for pneumonia i.e.164 (79.69\%), average knowledge for ANC i.e. 136(66.02\%) and poor knowledge of family planning 102(49.51\%). Record keeping practice of ASHA and other work like distribution of IFA tablet, chloroquine table, ANC checkup, vaccination, etc. work was satisfactory. Table no. 2

DISCUSSION: In this study majority (67.69\%) of the ASHA workers were in the age group of 20-29 years. Similar result was observed by others.4, 8 Thus majority of the ASHAs may be considered young and this may be strength for programme as they are energetic and may deliver better service with proper motivation and capacity building. ASHA envisage a total period of 23 days training in five episodes. It is said that ASHA training is a continuous one and that she develops the necessary skills \& expertise through continuous on the job training. ${ }^{9}$ Regarding level of education, most of ASHA workers had completed minimum 8th std but our study 35 ASHAs (17\%) had education less than 8th std. Another report shows percentage of ASHAs educated below 8th std as high as $32.8 \%{ }^{2}$ This can be explained by the fact that selection criteria are 8th Class and at some places it has been reduced to 5 th Class. ${ }^{8}$ Similar findings were obtained by others. ${ }^{2,10}$

As far as ASHAs knowledge about immunization was concerned, their overall response was poor immunization. Most of the ASHAs preferred helping in delivery and immunization. These activities are also associated with financial incentives. But many other jobs like counseling on family planning, referred for MTP, give TB drug etc. were drawing lesser attention probably due to lack of incentives. These could be areas requiring reorientation.

The study revealed that only $62.14 \%$ of the ASHAs received kits, immediately after training. Non-availability of kits is a matter of concern. Not surprisingly, finding of our study mimics the finding presented by 'Rapid appraisal of functioning of ASHA in Orissa'. ${ }^{8}$ Availability of drug kit helps ASHAs in not only attending some primary medical care needs, but also builds confidence of community in ASHAs as someone available in " hour of need".

CONCLUSION: In general ASHAs are satisfied and happy with the training. But their perception about the in job responsibilities appeared to be incomplete and improper. Many of them were not aware about their role in assisting ANM in village health planning, creating awareness on basic sanitation \& personal hygiene. Incentives in monitory terms and capacity building in the weak areas of training can act as driving force in delivering better health services. ASHAs do provide constellation of services and play a potential role in providing primary health care but still they need to put into practice their knowledge about while providing services and/or advice to negotiate health care for poor women and children.

\section{REFERENCES:}

1. Government of India, National Rural Health Mission (2005 -12), Mission Document. Available at: http://www.mohfw.nic.in/NRHM/Documents/Missio n_Document.pdf. Accessed on November 28th, 2012.

2. Assessment of ASHA and Janani Suraksha Yojana in Madhya Pradesh. Available at: www.cortindia.com/RP/RP-2007-0301.pdf. Accessed on November 7th, 2011.

3. Namshum N., Maternal and child health. Reading Material for ASHA. Book Number- 1. 1st ed. New Delhi: Ministry of Health and Family Welfare, Government of India; 2006. p 8. 
4. Srivastava DK, Prakash S, Adhish V, Nair KS, Gupta S, Nandan D. A study of interface of ASHA with the community and the service providers in Eastern Uttar Pradesh. Indian J Public Health 2009; 53(3):133-6.

5. Darshan K. Mahyavanshi, Mitali G. Patel, Girija Kartha, Shyamal K. Purani, Sunita S. Nagar. A cross sectional study of the knowledge, attitude and practice of ASHA workers regarding child health (under five years of age) in Surendranagar district. Healthline 2011; 2(2): 50-53.

6. Bhatnagar R, Singh K, Bir T, Datta U, Raj S, Nandan D. An assessment of performance based incentive system for ASHA Sahyogini in Udaipur, Rajasthan. Indian J Public Health 2009; 53(3):166-70.

7. Factors influencing utilization of ASHA services under NRHM in relation to maternal health In rural Lucknow. Indian J Community Med. 2010 July; 35(3): 414-419.

8. Assessment of ASHA and Janani Suraksha Yojana in Orissa. Available at: www.cortindia.com/RP\%5CRP- 2007-0303.pdf. Accessed on November 8th, 2011.

9. Training of ASHA. Available at: http://www.mohfw.nic.in/NRHM/asha.htm. Accessed on November 28th, 2012.

10. Jain N, Srivastava NK, Khan AM, Dhar N, Manon S, Adhish V, Nandan D. Assessment of functioning of ASHA under NRHM in Uttar Pradesh. Health and Population: Perspectives and Issues 2008; 31 (2): 132-40.

11. P K Garg, Anu Bhardwaj, Abhishek Singh, S. K. Ahluwalia. An evaluation of Asha worker's awareness and Practice of their responsibilities in rural Haryana: National Journal of Community Medicine 2013; 4(1); 76-80.

\begin{tabular}{|llll|}
\hline Study variables & \multicolumn{3}{c|}{ Knowledge(\%) } \\
\hline & Good & Average & Poor \\
\hline Malaria & $23(11.16)$ & $88(42.72)$ & $95(46.12)$ \\
\hline Diarrhea & $12(5.83)$ & $120(58.25)$ & $74(35.92)$ \\
\hline Pneumonia & $164(79.69)$ & $40(19.42)$ & $2(0.97)$ \\
\hline AIDS & $90(43.69)$ & $103(50)$ & $13(6.3)$ \\
\hline ANC & $69(33.50)$ & $136(66.02)$ & $1(0.48)$ \\
\hline Breast feeding & $53(25.73)$ & $80(38.83)$ & $73(35.44)$ \\
\hline Family planning & $26(12.62)$ & $78(37.86)$ & $102(49.51)$ \\
\hline Vdps & $31(15.05)$ & $74(35.86)$ & $101(49.02)$ \\
\hline Immunization schedule $38(18.45)$ & $67(32.52)$ & $85(41.26)$ \\
\hline
\end{tabular}

Table No. 1: Knowledge of ASHA 
ORIGINAL ARTICLE

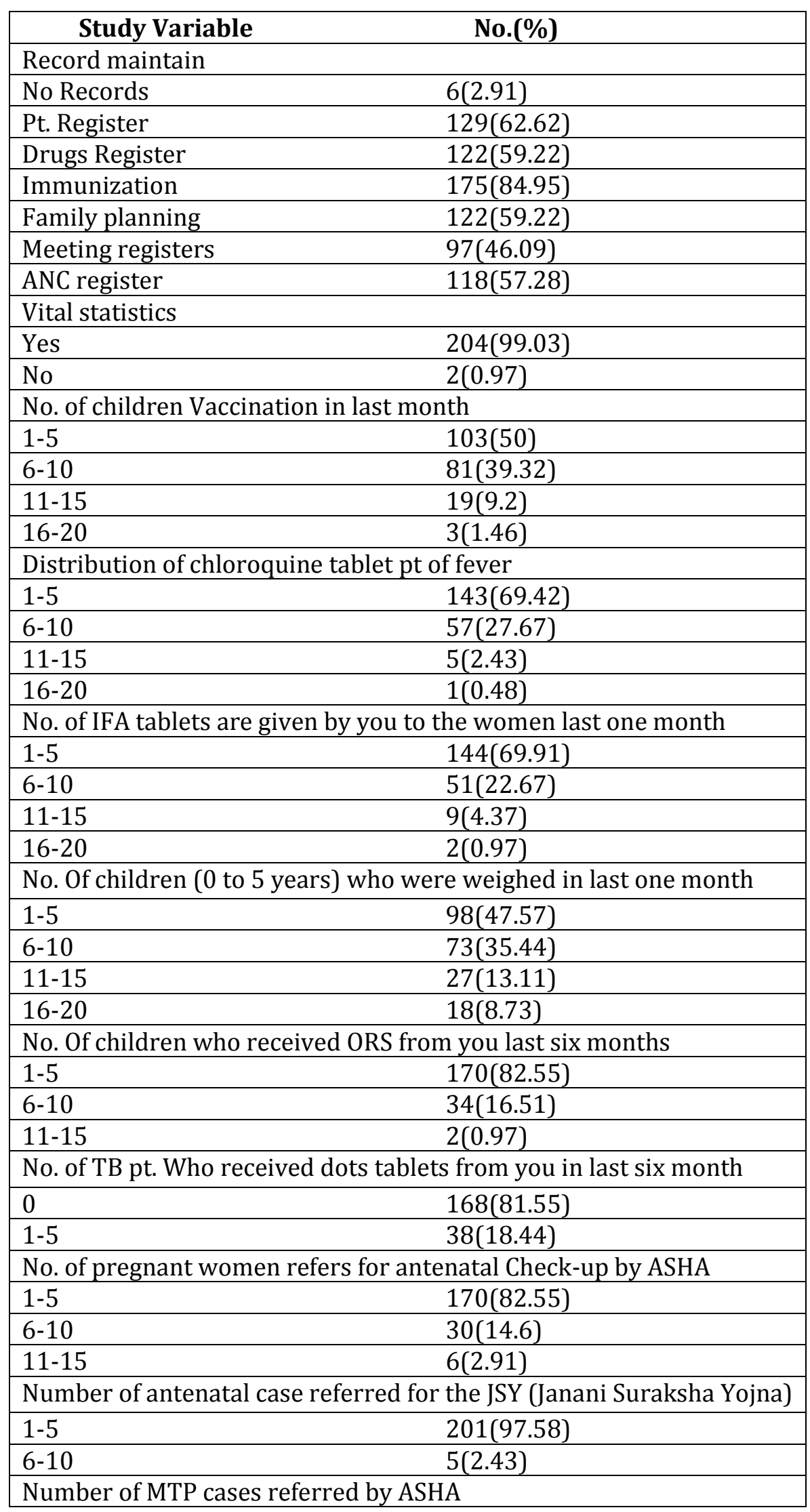




\section{ORIGINAL ARTICLE}

\begin{tabular}{|c|c|}
\hline Referred & $21(10.2)$ \\
\hline Not referred & 185(89.8) \\
\hline
\end{tabular}

\section{AUTHORS:}

1. Bhagwan Waskel

2. Sanjay Dixit

3. Rama Singodia

4. D.K. Pal

5. Manju Toppo

6. S.C. Tiwari

7. Satish Saroshe

\section{PARTICULARS OF CONTRIBUTORS:}

1. Assistant Professor, Department of Community Medicine, MGMMC, Indore.

2. Professor \& Head, Department of Community Medicine, MGMMC, Indore.

3. Assistant Professor, Department of Community Medicine, GMC, Bhopal.

4. Professor \& Head, Department of Community Medicine, GMC, Bhopal.
5. Associate Professor, Department of Community Medicine, GMC, Bhopal.

6. Ex-DME, MP Government.

7. Assistant Professor, Department of Community Medicine, MGMMC, Indore.

\section{NAME ADDRESS EMAIL ID OF THE CORRESPONDING AUTHOR:}

Dr. Bhagwan Waskel,

Assistant Professor,

Department of Community Medicine, MGMMC, A.B. Road,

Indore - 452001.

Email - drbhagwanwaskel@yahoo.com

Date of Submission: 30/12/2013.

Date of Peer Review: 31/12/2013.

Date of Acceptance: 08/01/2014.

Date of Publishing: 16/01/2014. 